\title{
Isolated digital vasculitis in a patient with rheumatoid arthritis: good response to tumour necrosis factor $\alpha$ blocking treatment
}

\author{
A A den Broeder, F H J van den Hoogen, L B A van de Putte
}

\begin{abstract}
Tumour necrosis factor $\alpha(\mathrm{TNF} \alpha)$ blocking agents are among the most promising new treatments for rheumatoid arthritis (RA). However, no data exist about the effect of these agents on extra-articular manifestations of RA. A patient is described with small vessel vasculitis that repeatedly responded well to treatment with the soluble p55 TNF $\alpha$ receptor fusion protein Ro 45-2081 (lenercept).

(Ann Rheum Dis 2001;60:538-539)
\end{abstract}

Symmetrical polyarthritis is the hallmark of rheumatoid arthritis (RA). In addition, pathology outside the joints can also be found. One of these so-called extra articular manifestations of RA is vasculitis. Vasculitis in RA usually affects small vessels and commonly involves the skin, causing nailfold infarcts, and in more severe cases digital gangrene and leg ulcers. ${ }^{1}$ Less frequently, vasculitis of small and medium sized arteries complicates RA and causes damage to peripheral nerves and internal organs. Prevalence of vasculitis in RA varies from 1 to $5 \%$ but postmortem studies show higher percentages up to $25 \% .^{2}$ Treatment of rheumatoid vasculitis depends on the size of the vessels affected and the impending organ damage.
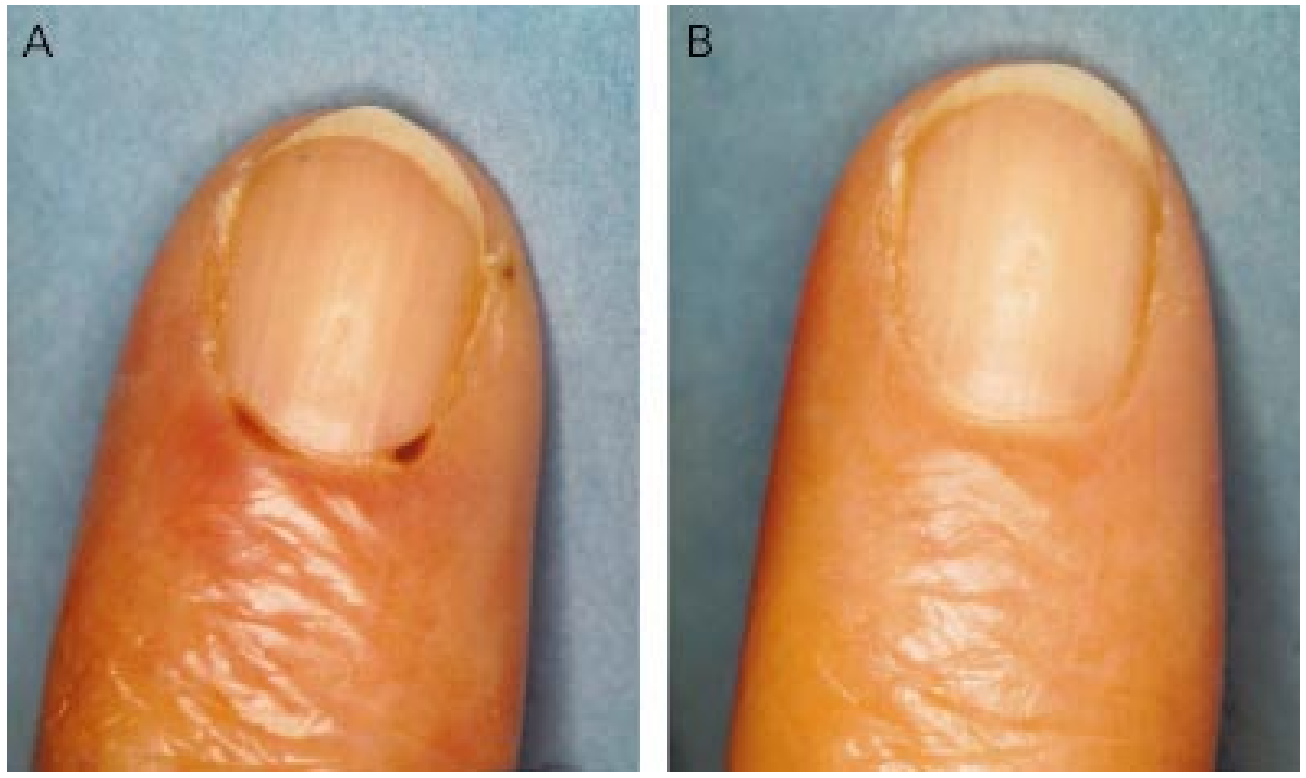

Figure 1 Before (A) and two weeks after (B) injection with lenercept (Ro 45-2081, an sTNFR:Fc p55 fusion protein). Small petechia and surrounding erythema are seen along the nailfold $(A)$. After injection, the lesions are no longer present and the erythema has dramatically improved (B).

High doses of corticosteroids may be necessary, often in combination with immunosuppressive agents, including azathioprine and cyclophosphamide, to allow for long term disease control and reduction of the corticosteroid dose. Treatment with these drugs is associated with considerable side effects.

In the past decade new agents have been developed for the treatment of autoimmune diseases. Among the most promising are tumour necrosis factor $\alpha(\mathrm{TNF} \alpha)$ blocking agents. Several agents that block TNF $\alpha$ have been developed and studied in patients with RA. ${ }^{3-5}$ TNF $\alpha$ blockade is achieved either with monoclonal antibodies against $\mathrm{TNF} \alpha$ or with fusion proteins containing human TNF receptors bound to an Fc component of a human IgG antibody. Although excellent efficacy in treatment of RA has been reported for several of these agents, no reports have thus far considered the effect of $\mathrm{TNF} \alpha$ scavenging on extra-articular manifestations. We describe a chance observation in a patient with RA and nailfold lesions, responding repeatedly to treatment with the anti-TNF $\alpha$ receptor fusion protein, lenercept.

\section{Case report}

A 46 year old woman was diagnosed with rheumatoid factor positive, erosive RA in 1982.

Department of

Rheumatology,

University Medical

Centre Nijmegen, The

Netherlands

A A den Broeder

F H J van den Hoogen

L B A van de Putte

Correspondence to: Dr A A den Broeder, Department of

Rheumatology, University

Medical Centre Nijmegen' PO Box 9101, 6500 HB

Nijmegen, The Netherlands

Accepted 16 January 2001 
From the beginning of her disease, antinuclear antibodies could be detected. Testing for disease-specific autoantibodies was negative on several occasions. Her medical history was unremarkable. In the following years she was treated unsuccessfully with hydroxychloroquine, intramuscular gold salts, D-penicillamine, azathioprine, methotrexate, and a combination of sulfasalazine and methotrexate. Because of progressive joint destruction she received shoulder prostheses on both sides, an elbow endoprosthesis left, total knee joint replacement on both sides, and a spondylodesis of the first and second cervical vertebra was performed. No extra-articular symptoms were present except for sicca complaints. Owing to the uncontrollable disease she was included in 1994 in a study with Ro 45-2081, a fusion protein combining two p55 TNF receptors with the Fc component of an IgG human antibody (lenercept). ${ }^{6}$ After a three month placebo controlled phase she was treated with $50 \mathrm{mg}$ lenercept intravenously every four weeks. Clinical response was impressive with swollen joint counts decreasing from 32 to five and $\mathrm{C}$ reactive protein (CRP) levels declining from $95 \mathrm{mg} / \mathrm{l}$ at baseline to $20 \mathrm{mg} / \mathrm{l}$ after the first injection. Low disease activity was sustained for the following years. Besides lenercept, her drug treatment consisted of oral prednisone $5 \mathrm{mg}$ a day and, occasionally, paracetamol $500 \mathrm{mg}$.

In the spring of 1999 she first noticed nailfold lesions on the fingers of both hands. These lesions disappeared after every injection of lenercept and reappeared three weeks thereafter when the effect of lenercept was decreasing (figs $1 \mathrm{~A}$ and $\mathrm{B}$ ). Clinical response indicated by a drop in joint counts and CRP was present two weeks after each anti-TNF $\alpha$ injection.

\section{Discussion}

We describe a patient with RA and small vessel vasculitis manifested by nailfold lesions responding to treatment with lenercept. The response has been well documented during two cycles of anti-TNF $\alpha$ administration. Although the role of TNF $\alpha$ in RA and systemic vasculitis, such as Kawasaki disease ${ }^{7}$ and Wegener's granulomatosis, ${ }^{8}$ is well established, its role in vasculitis complicating RA is less clear. In one study $\mathrm{TNF} \alpha$ levels were found to be increased in patients with small vessel cutaneous vasculitis without RA. ${ }^{9}$ Nailfold lesions in RA usually have a favourable outcome and generally do not require additional treatment. Thus far, little attention has been paid to extra-articular manifestations in studies examining the efficacy of anti-TNF $\alpha$ treatment in RA. The prompt disappearance of nailfold lesions after lenercept administration seen in our patient could be an indication that blocking of TNF $\alpha$ might be effective in more severe forms of vasculitis and possibly other extra-articular manifestations of RA, some of which are life threatening and currently treated with high doses of corticosteroids and immunosuppressive drugs.

1 Klippel JH, Dieppe PA, eds. Rheumatology. 2nd ed. London: Mosby, 1998:5.4.6.

2 Snowden N, Kay RA. Immunology of systemic rheumatoid disease. Br Med Bull 1995;51:437-48.

3 Maini R, St Clair EW, Breedveld F, Furst D, Kalden J, Weisman $M$, et al. Infliximab (chimeric anti-tumor necrosis factor alpha monoclonal antibody) versus placebo in rheumatoid arthritis patients receiving concomitant methotrexate: a randomized phase III trial. ATTRACT Study Group. a randomized phase III trial

Lancet 1999;354:1932-9.
4 Moreland LW, Baumgartner SW, Schiff MH, Tindall EA, Fleischmann RM, Weaver AL, et al. Treatment of rheumatoid arthritis with a recombinant human tumor necrosis factor receptor (p75)-Fc fusion protein [see comments]. N Engl J Med 1997;337:141-7.

5 van de Putte LBA, van Riel PLCM, den Broeder AA, Rau R, Sander O, Schattenkirchen $\mathrm{M}$, et al. A single dose placebo controlled phase I study of the fully human anti-TNF antiArthritis Rheum 1998;41:S57.

6 Richter WF, Gallati H, Schiller CD. Animal pharmacokinetics of the tumor factor receptor immunoglobulin fusion ics of the tumor factor receptor immunoglobulin fusion
protein lenercept and their extrapolation to humans. Drug Metab Dispos 1999;27:21-5.

7 Kamizone S, Yamada A, Higuchi T, Kato H, Itoh K. Analysis of tumor necrosis factor-alpha production and polymorphisms of the tumor necrosis factor-alpha gene in individuals with a history of Kawasaki disease. Pediatr Int 1999;41: $341-5$.

8 Noronha IL, Kruger C, Andrassy K, Ritz E, Waldherr R. In situ production of TNF-alpha, IL-1 beta and IL-2R in ANCA positive glomerulonephritis. Kidney Int 1993;43: 682-92.

9 Papi M, Didona B, De Pita O, Frezzolini A, Di Giulio S, De Matteis W, et al. Livedo vasculopathy vs small vessel cutaneous vasculitis: cytokine and platelet P-selectin studies. Arch Dermatol 1998;134:447-5. 